\title{
Long- and medium-term ozone effects on lung growth including a broad spectrum of exposure
}

\author{
G. Ihorst*, T. Frischer", F. Horak", M. Schumacher ${ }^{\star}$, M. Kopp*, J. Forster ${ }^{+}$, J. Mattes*, J. Kuehr*
}

Long- and medium-term ozone effects on lung growth including a broad spectrum of exposure. G. Ihorst, T. Frischer, F. Horak, M. Schumacher, M. Kopp, J. Forster, J. Mattes, J. Kuehr. (C) ERS Journals Ltd 2004.

ABSTRACT: The effects of semi-annual and $3.5 \mathrm{yr}$ mean ozone $\left(\mathrm{O}_{3}\right)$ concentrations on children's forced vital capacity (FVC) and forced expiratory volume in one second (FEV1) were assessed over a study period of 3.5 yrs in 2,153 schoolchildren from 15 study sites in South Western Germany and Lower Austria.

Spirometric parameters were assessed twice a year, and differences between consecutive measurements divided by days were considered as a measure of lung growth. Exposure was analysed in four classes, separately for winter and summer (semiannual mean $\mathrm{O}_{3}$ concentrations $22-30,30-38,38-46,46-54$ parts per billion (ppb) in summer and 4-12, 12-20, 20-28, 28-36 ppb in winter).

Regression methods for repeated measurements were used, and these revealed a significantly lower FVC (FEV1) increase estimated at $-19.2(-18.5) \mathrm{mL} \cdot 100$ days $^{-1}$ for semi-annual mean $\mathrm{O}_{3}$ exposure in summer between 46 and $54 \mathrm{ppb}$ compared to exposure between 22 and $30 \mathrm{ppb}$. However, in winter, the estimated difference in FVC (FEV1) was $16.4(10.9) \mathrm{mL} \cdot 100$ days $^{-1}$ between the semi-annual $\mathrm{O}_{3}$ class $28-36 \mathrm{ppb}$ and the 4-12 ppb class. By means of linear regression the study found that there was no association between growth rates and mean summer $\mathrm{O}_{3}$ for FVC and FEV1 over a $3.5 \mathrm{yr}$ period.

The authors conclude that medium-term effects on schoolchildren's lung growth are possibly present, but are in the long-term not detectable for forced vital capacity and forced expiratory volume in one second over a $3.5 \mathrm{yr}$ period due to partial reversibility. Eur Respir J 2004; 23: 292-299.
*University Children's Hospital, "Institute for Medical Biometry and Medical Informatics and ${ }^{+}$St. Josefs Hospital, Freiburg, Germany. ${ }^{\#}$ University Children's Hospital, Vienna, Austria.

Correspondence: G. Ihorst

Institute for Medical Biometry and Medical Informatics

Stefan-Meier Str. 26

D-79106 Freiburg

Germany

Fax: 497612036688

E-mail: Gabi@imbi.uni-freiburg.de

\section{Keywords: Children \\ long-term exposure \\ lung growth}

ozone

Received: February 272003

Accepted after revision: September 302003
Various studies have demonstrated the effects of short-term ozone $\left(\mathrm{O}_{3}\right)$ exposure on children's respiratory health or lung function parameters such as forced vital capacity (FVC), forced expiratory volume in one second (FEV1) or peak expiratory flow (PEF). The expression short-term exposure refers to time spans of $1 \mathrm{~h}$ to several days before lung function is tested. Medium-term exposure means time periods of several months and long-term exposure refers to years (without representation of seasonal effects). Children are considered to be at higher risk than adults to possible damage caused by air pollution, since they spend more time outdoors, are more active and their growing lungs might be more susceptible.

Some of these studies were conducted under conditions that were natural but with high exposure values, i.e. lung function measurements were made before and after physical exercise [1-3]. Some studies took place in summer camps where children spent much time outside and were thus exposed to air pollution most of the time. A combined analysis of six summer camp studies showed a significant negative effect of $\mathrm{O}_{3}$ on FEV1 but not on PEF [4]. Other investigators studying children during normal daily activities found negative associations between $\mathrm{O}_{3}$ and lung function measurements [5-13].

To the best of the authors' knowledge only a few longitudinal investigations have been made concerning the longer-lasting effects of $\mathrm{O}_{3}$. A preliminary analysis of the first

For editorial comments see page 185. cross section of a study with schoolchildren from 12 South California communities suggested negative associations of chronic $\mathrm{O}_{3}$ exposure and expiratory flow rates [14]. During the follow-up part of the study no further $\mathrm{O}_{3}$ effect could be determined [15]. The same study group investigating a different cohort over a 4-yr period observed an $\mathrm{O}_{3}$ effect on peak expiratory flow rate (PEFR) [16]. KINNEY et al. [17] found a seasonal decline in respiratory function in healthy young adults working outside over one summer period in the presence of $\mathrm{O}_{3}$ and particulate matter. Associations between ambient $\mathrm{O}_{3}$ exposure and lung growth in schoolchildren were reported in studies from Austria [18].

In order to investigate chronic effects of inhaled air pollutant on lung growth repeated measurements on each child are required $[19,20]$. Therefore two co-conducted studies were carried out in 15 communities in Germany (Black Forest) and Lower Austria with different levels of ambient $\mathrm{O}_{3}$ concentrations, performing repeated spirometry measurements on elementary schoolchildren twice a year (in spring and autumn). Earlier results of the first three study years of the Austrian study alone [18] and a combined analysis of Austrian data from the first 2 yrs together with an earlier German study [21] had already shown signs of delayed lung growth in summer and a catch-up in winter for children from the regions with higher seasonal $\mathrm{O}_{3}$ exposure. The current authors are now able to present data from a 4-yr time period for geographical areas representing a large spectrum of outdoor $\mathrm{O}_{3}$ concentrations. 
In total 6,814 spirometries were obtained from 1,114 Austrian children and 6,105 spirometries from 1,039 German children. The difference between 2 measurements divided by time is considered to be an adequate description of lung growth. The current article focuses on two questions. Does high $\mathrm{O}_{3}$ exposure result in decreased lung growth over a period up to 3.5 yrs (long-term)? Does children's lung growth vary with seasonal exposure to $\mathrm{O}_{3}$ (medium-term)?

\section{Methods}

\section{Study design}

Study sites were selected according to 1991-1993 annual mean $\mathrm{O}_{3}$ levels in order to represent a broad spectrum of ambient $\mathrm{O}_{3}$ exposure. To avoid confounding low levels of other pollutants from traffic and industry were required. Data was provided by governmental air pollution surveillance in both countries.

Initially 2,251 children were enrolled (Austria: 1150; Germany: 1101). Over a time period of 3.5 yrs two semi-annual lung function measurements were obtained (in spring and autumn) from schoolchildren initially in first and second primary school classes in Austria (Amstetten: altitude $270 \mathrm{~m}$, St Valentin: 242 m, Krems: 190 m, Heidenreichstein: 560 m, Gänserndorf: $161 \mathrm{~m}$, Mistelbach: $250 \mathrm{~m}$, Wiesmath: $738 \mathrm{~m}$, Bruck: $210 \mathrm{~m}$, Pöllau: station site Masenberg at $1180 \mathrm{~m}$ ) and South Western Germany (Aalen $420 \mathrm{~m}$, Ehingen $530 \mathrm{~m}$, Tuttlingen $643 \mathrm{~m}$, Villingen $705 \mathrm{~m}$, Freudenstadt $750 \mathrm{~m}$, Welzheim $500 \mathrm{~m}$ ). One German and 7 Austrian sites were rural and small town communities with a population size $<12,000 ; 4$ German and 2 Austrian sites were towns with a population size of 12,000 35,000 ; one German site had a population size of $\sim 65,000$.

The study was carried out from April 1994 to October 1997 in Austria and from February 1996 to October 1999 in Germany. Questionnaires, lung function and skin-prick test perfomance were standardised before the beginning of the study. In Germany, three teams of fieldworkers collected data. All lung function tests in Austria were performed by two trained medical students over the whole 3.5 yrs. Skin-prick tests were performed by a team of five doctors and medical students.

Teams and devices were changed systematically between study sites to avoid a bias caused by a fieldworker or device effect. All technical details (spirometry protocol, hardware, software, calibration of the spirometer) were standardised before the beginning of the study, and all staff were trained centrally. The study protocol was approved by the local ethics committee and written consent was obtained from the parents.

\section{Pulmonary function testing}

Pulmonary function tests took place during or after school time using a Masterscope (Software Release 4.0; Erich Jaeger, Würzburg, Germany). The instruments were calibrated daily. Every child performed two forced expiratory manoeuvres according to American Thoracic Society (ATS) guidelines, in a standing position wearing a noseclip. Two flow/volume curves were accepted as reproducible if the difference between FVC measurements was $\leqslant 5 \%$. The highest FVC and FEV1 values were then selected for statistical analysis. Absolute values as well as values as per cent predicted ( $\%$ pred) were reported (DOCKERY et al. [22]).

\section{Questionnaires}

Information concerning housing conditions, parental education, diagnosis of asthma or recurrent wheezy bronchitis and history of respiratory symptoms was collected using questionnaires which were based on the standardised questions of the International Study of Asthma and Allergies in Childhood (ISAAC) questionnaire and filled in by the parents at the beginning of the study [23]. Further questionnaires concerning occurrence of respiratory symptoms during the study period were distributed each year and at the end of the study.

\section{Skin-prick tests}

Skin-prick tests were performed on the forearm with extracts from hazel, birch and grass pollens, cat and dog dander, house-dust mite, negative control: sodium chloride $\left(9 \mathrm{~g} \cdot \mathrm{L}^{-1}\right)$, positive control: histamine hydrochloride $\left(10 \mathrm{mg} \cdot \mathrm{mL}^{-1}\right)$ (Alk Scherax, Hamburg, Germany). Skin reactions were evaluated after $15 \mathrm{~min}$. A weal diameter $>2 \mathrm{~mm}$ and at least half as large as the histamine weal was considered as a valid positive reaction [24].

\section{Air pollution and exposure data}

The concentrations of $\mathrm{O}_{3}$, nitrogen dioxide $\left(\mathrm{NO}_{2}\right)$ and total suspended particles (TSP)/particles with a 50\% cut-off aerodynamic diameter of $10 \mu \mathrm{m}$ (PM10) were obtained as 30 -min means from fixed monitoring stations located in the vicinity of the study site and run by local authorities. For $\mathrm{O}_{3}$ the ultraviolet (UV) absorption method was used (Germany: KS-212-1012.10, Vorabscheider, Kalman System, Hungary; Austria: ML 8810 Monitor Labs, San Diego, CA, USA).

\section{Statistical analysis}

As a measure of lung growth [18] the difference between two consecutive FVC and FEV1 values for each child, divided by the number of days between the tests was calculated. The daily increase was then standardised for a period of 100 days $\left(\mathrm{mL} \cdot 100\right.$ days $\left.^{-1}\right)$. The effect of medium-term $\mathrm{O}_{3}$ exposure on lung growth was analysed by means of linear regression models, with lung growth as the dependent variable and $\mathrm{O}_{3}$ concentration averaged over each of the four summer periods (referred to as semi-annual mean $\mathrm{O}_{3}$ exposure) as independent variable, further adjusting for sex, age and height at start of the time period, passive smoke exposure, short-term $\mathrm{O}_{3}$ exposure at start and end of the time period, and time period. Short-term $\mathrm{O}_{3}$ exposure was measured as maximum exposition on the day before lung function tests were performed. "Time period" consists of dummy variables for each season, thus reflecting effects that arise due to the longitudinal character of the study.

A regression model was constructed which described the relationship between $\mathrm{O}_{3}$ exposure and lung growth directly, providing semi-annual $\mathrm{O}_{3}$ means as independent variable. Semi-annual $\mathrm{O}_{3}$ means differ between the 15 study sites and the four summer periods, but are equal within a given study site and study period. Thus the difference in lung growth caused hypothetically by a certain amount of increase in semiannual $\mathrm{O}_{3}$ concentrations was estimated.

Linearity of the relationship was investigated by means of the method of fractional polynomials [25]. Here, a set of polynomial transformations of the independent variable (semi-annual mean $\mathrm{O}_{3}$ concentration) is provided, and the transformation fitting best is selected. Based on the results of the fractional polynomial selection precedure, exposure classes were formed with equal ranges of concentrations and similar numbers of observations. $\mathrm{O}_{3}$ exposure classes were 
constructed separately for summer (April 1st until September 30th) and winter (October 1st until March 31st).

Further, an area-based categorisation with regions of high $(\mathrm{H} ; 32.0-40.6$ parts per billion (ppb)), medium (M; 24.1$30.7 \mathrm{ppb}$ ) or low (L; 20.0-21.3 ppb) exposure was used. The definition of these three $\mathrm{O}_{3}$ exposure categories was arbitrarily made on the basis of $\mathrm{O}_{3}$ means obtained for the total study period. In the regression model the area-based $\mathrm{O}_{3}$ exposure categories served as independent and semi-annual lung growth as dependent variable. The intention of this analysis is to investigate sensitivity of the main model.

Further variables to be discussed as possibly influencing were medium-term $\mathrm{NO}_{2}$ and sulphur dioxide $\left(\mathrm{SO}_{2}\right)$ exposition (mean values for the respective time period), fieldworkers performing the tests, and rhinitis observed when performing the test. Furthermore, a possible effect due to merging two studies and possible interactions of the "study effect" with an $\mathrm{O}_{3}$ effect were taken into consideration.

Regression models were calculated first for each season separately. Then one common model was built for the four summer half-years and one model for the three winter halfyears. This was done by applying the generalised estimation equation (GEE) method to account for the correlation of repeated measurements from each child [26]. To apply GEE, a so-called working correlation matrix must be specified. Estimates with asymptotically correct standard errors are then obtained independent of the choice of the working correlation. An exchangeable correlation structure was chosen which corresponds to a model including a random intercept term for each child. However, further choices (AR(1) and unstructured) were investigated.

Lung growth over the total study period of $3.5 \mathrm{yrs}$ was assessed in a manner similar to that proposed by GAUDERMAN and coworkers $[15,16]$ : in a first step, growth rates were obtained by performing individual regressions for $\log (\mathrm{FVC})$ and $\log (\mathrm{FEV} 1)$ as dependent variables, $\log$ (height) and shortterm $\mathrm{O}_{3}$ exposure as independent variables. This choice of modelling pre-adolescent lung growth has been strongly recommended by WARE and WEISS [27]. In a second step, individual regression slopes were analysed as dependent variables in a regression model with $\mathrm{O}_{3}$ exposure averaged over four summer periods, sex, passive smoke exposure, and age at first lung function test as independent variables.
Only children with at least six lung function tests were included in these calculations in order to obtain reliable estimates covering a great part of the total observation period.

\section{Results}

With regard to medium-term effects, 2,153 children providing at least two consecutive lung function tests were analysed. There were in total 12,919 observations ("pairs" of two consecutive spirometries) on lung growth to be analysed. Of these 1,282 children had seven, 322 had six, 207 had five, 121 had four, 99 had three, 75 had two, and 47 had one pair of observations.

The main characteristics of the study population are described in table 1. Median age is 7.6 yrs on March 1st of the first study year; it is highest in Villingen and Aalen due to a larger proportion of children recruited from class two and lowest in Pöllau where investigations started later.

Asthma at the start of the study (defined as either diagnosed by a doctor or a positive answer to the ISAAC question "has your child ever had asthma") ranged between $1.2 \%$ (Heidenreichstein/Austria) and 12.8\% (Amstetten/Austria). A possible explanation of such a broad range might be differing practices of local physicians when using the expressions "asthma" and "recurrent wheezing bronchitis". Sensitisation to pollen allergens also showed a large variation, between $6.8 \%$ (Wiesmath/Austria, Gänserndorf/Austria) and 28.8\% (Ehingen/Germany).

In the total population passive smoke exposure was reported by $34.9 \%$ and ranged between $22.4 \%$ (Wiesmath/ Austria) and 46.5\% (Krems/Austria). FVC \% pred at the first investigation was $107.8 \%$ in the total population, ranging between 103.5\% (Mistelbach/Austria) and 111.2\% (Freudenstadt/Germany). FEV1 \% pred ranged between 105.6\% (St. Valentin/Austria) and 110.3\% (Pöllau/Austria). Median FVC $\%$ pred (FEV1 \% pred) was $110.3 \%(108.5 \%)$ in German regions and $105.0 \%(107.8 \%)$ in Austrian regions. Spearman correlation between FVC \% pred and FEV1 \% pred at the first investigation showed a similar relationship in Austria $(\mathrm{r}=0.82$, $\mathrm{p}<0.0001)$ and in Germany $(\mathrm{r}=0.76, \mathrm{p}<0.0001)$.

The allocation of the study sites into area-based categories (high $(\mathrm{H})$, medium $(\mathrm{M})$, low $(\mathrm{L})$ ) according to the mean $\mathrm{O}_{3}$

Table 1.-Main characteristics of the study population

\begin{tabular}{|c|c|c|c|c|c|c|c|c|}
\hline & $\begin{array}{l}\text { Subjects } \\
\mathrm{n}\end{array}$ & $\begin{array}{c}\text { Sex } \\
\text { female } \%\end{array}$ & Age years & $\begin{array}{l}\text { Passive smoke } \\
\text { exposure } \%\end{array}$ & $\begin{array}{l}\text { Asthma at } \\
\text { start of the } \\
\text { study } \%\end{array}$ & $\begin{array}{l}\text { Sensitisation } \\
\text { to pollen } \\
\text { allergens } \%\end{array}$ & $\begin{array}{l}\text { FVC } \% \text { pred }^{\#} \text { at } \\
\text { start of study }\end{array}$ & $\begin{array}{l}\text { FEV1 } \% \text { pred }^{\#} \\
\text { at start of study }\end{array}$ \\
\hline Total population & 2153 & 48.9 & $7.6(6.5-8.8)$ & 34.9 & & 14.9 & $107.8(89.6$ & $107.9(88$. \\
\hline Amstetten (A) & 134 & 3 & $7.5(6.6-8.5)$ & 40.5 & 12.8 & 13.3 & $105.9(87.4-122.8)$ & $107.7(89.0-125.5)$ \\
\hline St. Valentin (A) & 116 & 51.7 & $7.7(6.7-8.9)$ & 31.3 & 8.8 & 12.6 & $104.3(84.8-119.0)$ & $105.6(89.1-122.4)$ \\
\hline Krems (A) & 161 & 47.2 & $7.6(6.6-8.5)$ & 46.5 & 6.3 & 9.0 & $106.1(89.5-127.7)$ & $107.2(87.0-126.0)$ \\
\hline Tuttlingen $(G)$ & 231 & 48.1 & $7.8(6.8-9.0)$ & 45.8 & 3.5 & 20.2 & $107.8(84.1-125.8)$ & $107.1(83.7-124.8)$ \\
\hline Aalen $(G)$ & 89 & 53.9 & $8.3(7.6-9.3)$ & 42.7 & 4.8 & 17.9 & $110.3(94.5-133.6)$ & $107.6(85.3-127.2)$ \\
\hline Villingen (G) & 35 & 37.1 & $8.3(7.5-10.0)$ & 38.2 & 2.9 & 11.8 & $107.7(96.8-124.1)$ & $109.4(91.9-132.7)$ \\
\hline Gänserndorf (A) & 98 & 49.0 & $7.6(6.7-8.6)$ & 38.3 & 5.2 & 6.8 & $104.1(83.7-131.1)$ & $107.2(91.2-123.6)$ \\
\hline Ehingen $(G)$ & 73 & 54.8 & $7.7(6.9-9.0)$ & 32.9 & 2.7 & 28.8 & $111.0(93.4-131.5)$ & $108.5(92.1-126.0)$ \\
\hline Mistelbach (A) & 152 & 44.7 & $7.6(6.6-8.7)$ & 30.3 & 4.0 & 8.9 & $103.5(86.1-128.1)$ & $105.4(85.9-132.5)$ \\
\hline Heidenreichstein (A) & 83 & 50.6 & $7.6(6.7-8.8)$ & 32.9 & 1.2 & 11.6 & $105.5(90.0-123.1)$ & $107.7(89.3-125.5)$ \\
\hline Bruck (A) & 73 & 52.1 & $7.5(6.6-8.8)$ & 43.1 & 4.1 & 14.1 & $103.9(93.8-119.6)$ & $104.5(90.9-119.8)$ \\
\hline Welzheim (G) & 216 & 51.4 & $7.8(6.8-9.0)$ & 31.9 & 6.5 & 20.9 & $110.0(95.8-125.3)$ & $107.9(88.9-128.6)$ \\
\hline Freudenstadt (G) & 395 & 49.4 & $7.7(6.8-8.8)$ & 28.7 & 3.3 & 18.1 & $111.2(91.9-125.6)$ & $109.4(89.6-128.2)$ \\
\hline Wiesmath (A) & 126 & 47.6 & $7.6(6.5-8.4)$ & 22.4 & 4.0 & 6.8 & $103.8(90.1-119.3)$ & $109.1(91.9-126.3)$ \\
\hline Pöllau $^{+}(\mathrm{A})$ & 171 & 49.7 & $6.6(5.6-7.7)$ & 30.6 & 8.2 & 8.1 & $106.5(88.8-127.6)^{\S}$ & $110.3(87.1-129.9)^{\S}$ \\
\hline
\end{tabular}

Data are presented as median (5\%-95\% quantile) unless otherwise indicated. FVC: forced vital capacity; FEV1: forced expiratory volume in one second; A: Austria, G: Germany; ${ }^{+}$: Investigation at Pöllau started later (autumn 1994); ${ }^{\text {: }}$ data from 2 nd investigation autumn 1994; ${ }^{\#}$ : predicted value calculated according to Dockery. 


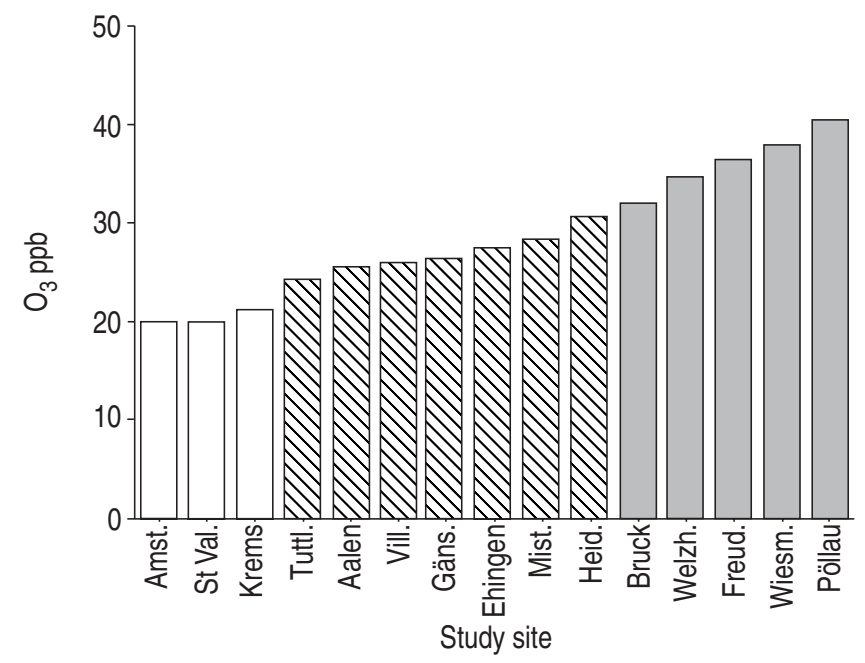

Fig. 1. - Mean 3.5 yearly ozone $\left(\mathrm{O}_{3}\right)$ concentrations (parts per billion $(\mathrm{ppb})$ ) in study sites divided into $\mathrm{O}_{3}$ exposure categories: high $(\mathrm{H}$; $\square)$, medium $(\mathrm{M} ; \mathbb{\mathbb { Q }}$ ) or low (L; $\square$ ) exposure.

concentration during the entire study period is shown in figure 1. Air pollution data stratified for the consecutive half years of the study period are presented in table 2. The $\mathrm{O}_{3}$ concentrations of the half years (table 2) represent the same order as the data for the entire study period (fig. 1). Slightly higher $\mathrm{O}_{3}$ values can be observed in the first two study summers $\left(\mathrm{O}_{3}\right.$ concentration averaged over all study sites is $36.6 \mathrm{ppb}$ ) than in the last two study summers (mean $\mathrm{O}_{3}$ concentration is $35.1 \mathrm{ppb}$ ). Different measurements of particulate matters were employed in Austria (TSP) and Germany (PM10), and no measurements exist for Welzheim, Gänserndorf and Wiesmath (table 2).

Figures 2 and 3 show lung volume increases calculated as described above in $\mathrm{mL} \cdot 100$ days $^{-1}$ for the area-based exposure categories: L, $\mathrm{M}$ or $\mathrm{H}$ exposure and for seven investigated study periods (four summer and three winter periods). In the

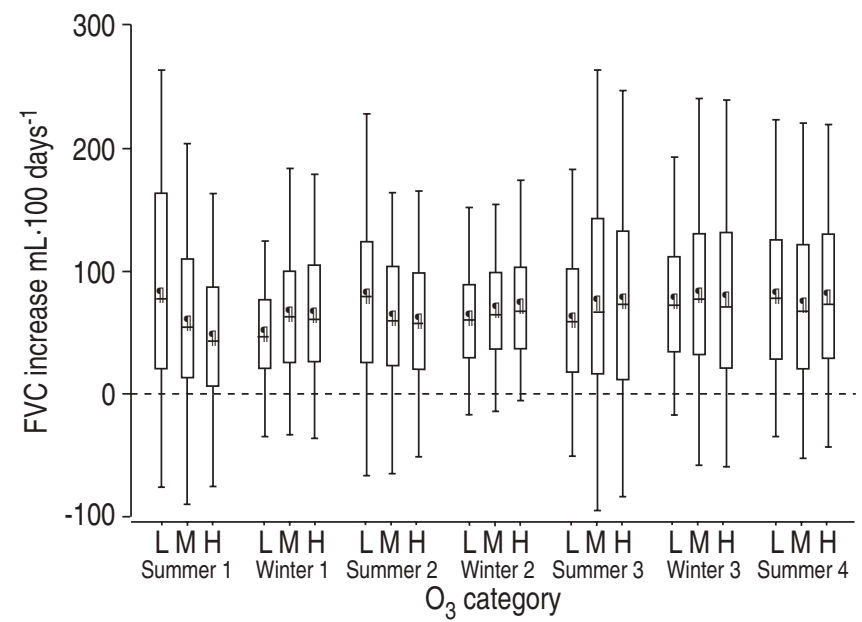

Fig. 2.-Increase in forced vital capacity (FVC) values over the seven study periods in the three area-based ozone $\left(\mathrm{O}_{3}\right)$ exposure categories (L: low; M: medium; H: high). The boxes include the interval between the $25 \%$ - and $75 \%$-quantile, the extremes represent the $5 \%$ - and $95 \%$ quantile, the median is shown as a horizontal line in the middle of the box and the mean as a symbol $\left({ }^{\top}\right)$.

low exposure category, a higher FVC increase in the first two summer periods and a smaller increase in the first two winter periods compared to the other exposure categories was observed (fig. 2). In the third summer period a lower increase in the low exposure category was found, and in the last two periods (winter three and summer four) no clear tendency for any of the exposure categories was detectable. Increases in FEV1 show a similar pattern over time (fig. 3).

In order to analyse the relationship between $\mathrm{O}_{3}$ exposure and lung growth, multivariate regression models for the influence of $\mathrm{O}_{3}$ exposure (area-based categories) on the lung volume increases were constructed for each time period separately (data not shown). The results of these regressions reflect those presented in figures 2 and 3 .

Table 2. - Air pollution assessment: median of half hourly concentrations

Amst. St.Val. Krems Tuttl. Aalen Vill. Gäns. Ehing. Mistel. Heid. Bruck Welz. Freud. Wies. Pöllau

\begin{tabular}{|c|c|c|c|c|c|c|c|c|c|c|c|c|c|c|c|}
\hline $\mathrm{O}_{3}$ summer 1 & 24 & 27 & 30 & 30 & 27 & 37 & 35 & 31 & 35 & 38 & 41 & 41 & 44 & 49 & 44 \\
\hline $\mathrm{O}_{3}$ winter 1 & 5 & 10 & 12 & 6 & 9 & 6 & 18 & 12 & 18 & 23 & 22 & 22 & 24 & 32 & 31 \\
\hline $\mathrm{O}_{3}$ summer 2 & 25 & 23 & 24 & 31 & 34 & 31 & 31 & 36 & 35 & 35 & 36 & 44 & 43 & 46 & 48 \\
\hline $\mathrm{O}_{3}$ winter 2 & 9 & 10 & 9 & 12 & 13 & 15 & 15 & 14 & 19 & 23 & 19 & 22 & 29 & 25 & 34 \\
\hline $\mathrm{O}_{3}$ summer 3 & 22 & 21 & 21 & 35 & 36 & 34 & 29 & 36 & 31 & 34 & 36 & 41 & 44 & 41 & 45 \\
\hline $\mathrm{O}_{3}$ winter 3 & 7 & 8 & 8 & 14 & 13 & 17 & 16 & 18 & 16 & 21 & 23 & 23 & 31 & 25 & 32 \\
\hline $\mathrm{O}_{3}$ summer 4 & 27 & 17 & 17 & 30 & 29 & 36 & 31 & 33 & 33 & 37 & 38 & 44 & 43 & 39 & 49 \\
\hline $\mathrm{NO}_{2}$ summer 1 & 11 & 8 & 11 & 9 & 9 & 7 & 7 & 7 & 6 & 5 & 4 & 3 & 5 & 3 & 2 \\
\hline $\mathrm{NO}_{2}$ winter 1 & 17 & 10 & 15 & 18 & 17 & 13 & 10 & 14 & 8 & 5 & 7 & 9 & 9 & 8 & 3 \\
\hline $\mathrm{NO}_{2}$ summer 2 & 10 & 9 & 11 & 9 & 11 & 7 & 5 & 7 & 5 & 3 & 4 & 4 & 6 & 1 & 3 \\
\hline $\mathrm{NO}_{2}$ winter 2 & 16 & 14 & 16 & 17 & 18 & 14 & 10 & 13 & 8 & 6 & 8 & 8 & 8 & 3 & 4 \\
\hline $\mathrm{NO}_{2}$ summer 3 & 10 & 5 & 4 & 8 & 10 & 7 & 5 & 7 & 6 & 4 & 3 & 4 & 5 & 5 & 2 \\
\hline $\mathrm{NO}_{2}$ winter 3 & 10 & 7 & 12 & 17 & 16 & 13 & 10 & 13 & & 5 & 7 & 9 & 8 & & 2 \\
\hline $\mathrm{NO}_{2}$ summer 4 & 7 & 4 & 2 & 8 & 10 & 6 & 6 & 7 & & 4 & 4 & 4 & 6 & & 2 \\
\hline PM10/TSP sum.1 & 30 & 26 & 30 & 14 & 19 & 16 & & 19 & & & 30 & & 15 & & 15 \\
\hline PM10/TSP win.1 & 20 & 26 & 30 & 18 & 30 & 17 & & 21 & & & 20 & & 14 & & 7 \\
\hline PM10/TSP sum.2 & 20 & 25 & 30 & 14 & 26 & 15 & & 17 & 20 & & 20 & & 16 & & 15 \\
\hline PM10/TSP win. 2 & 40 & 35 & 40 & 17 & 27 & 19 & & 21 & 35 & & 50 & & 15 & & 11 \\
\hline PM10/TSP sum. 3 & 20 & 24 & 30 & 13 & 22 & 17 & & 15 & 20 & 20 & 20 & & 16 & & 14 \\
\hline PM10/TSP win. 3 & 40 & 30 & 30 & 17 & 24 & 24 & & 17 & 20 & 20 & 30 & & 12 & & 9 \\
\hline PM10/TSP sum.4 & 30 & 23 & 30 & 12 & 21 & 17 & & 15 & 20 & 20 & 20 & & 15 & & 14 \\
\hline
\end{tabular}

Ozone $\left(\mathrm{O}_{3}\right)$ in parts per billion (ppb), nitrogen dioxide $\left(\mathrm{NO}_{2}\right)$ in ppb; total suspended particles (TSP) and particles with a $50 \%$ cut-off aerodynamic diameter of $10 \mu \mathrm{m}$ (PM10) in $\mu \mathrm{g} \cdot \mathrm{m}^{-3}$; Sum: summer; win: winter; TSP data available for Amstetten, St.Valentin, Krems, Mistelbach, Heidenreichstein, Bruck, Pöllau; PM10 data available for Tuttlingen, Aalen, Villingen, Ehingen, Freudenstadt. 


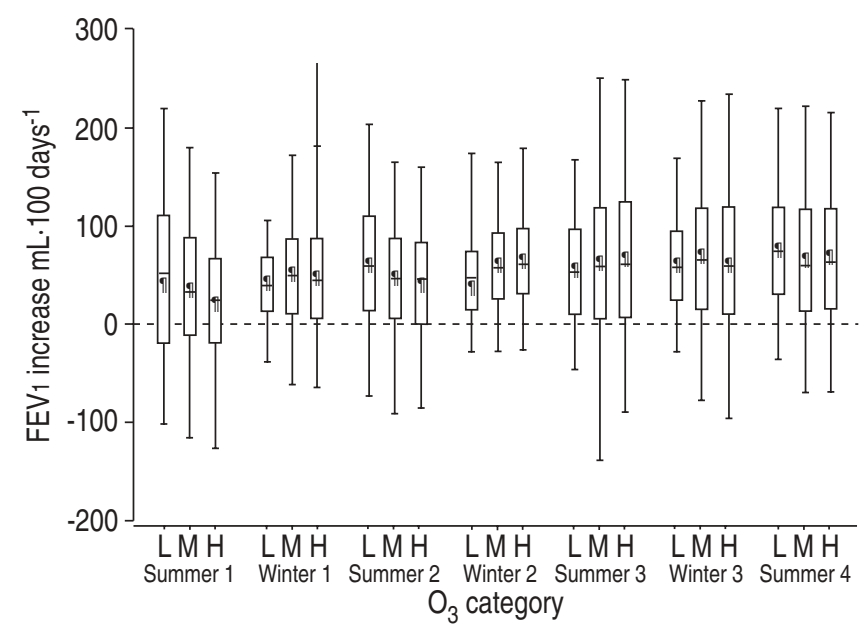

Fig. 3.-Increase in forced expiratory volume in one second (FEV1) increase values over the seven study periods in the three area-based ozone $\left(\mathrm{O}_{3}\right)$ exposure categories (L: low; $\mathrm{M}$ : medium; $\mathrm{H}$ : high). The boxes include the interval between the $25 \%$ - and $75 \%$-quantile, the extremes represent the 5\%- and $95 \%$-quantile, the median is shown as a horizontal line in the middle of the box and the mean as a symbol $\left(^{\circ}\right)$.

Table 3 shows the common regression analysis of the four summer periods and the three winter periods, analysing lung volume increases as the dependent variable and semi-annual mean $\mathrm{O}_{3}$ concentrations as the independent variable of interest. Models were adjusted for sex, age and height at start of the time period, passive smoke exposure, short term $\mathrm{O}_{3}$ exposure and time period as further independent variables.

Linearity of the relationship between semi-annual mean $\mathrm{O}_{3}$ concentrations and lung growth was investigated via fractional polynomials with the same type of regression model as above, but systematically introducing nonlinear transformations

Table 3. - Parameter estimates from generalised estimation equation models ${ }^{\#}$ for semi-annual ozone $\left(\mathrm{O}_{3}\right)$ means, divided in classes (pooled analysis for seasons)

Increase in:

Parameter estimates for increase $\left(\mathrm{mL} \cdot 100\right.$ days $\left.^{-1}\right)$ for semi-annual $\mathrm{O}_{3}$ means compared to "46-54 ppb" (summer) or to "28-36 ppb" (winter)

\begin{tabular}{lc}
\hline FVC summer & \\
$22-30 \mathrm{ppb}$ & $19.2(10.6-27.8)$ \\
$30<38 \mathrm{ppb}$ & $15.5(7.0-24.0)$ \\
$38-<6 \mathrm{ppb}$ & $19.2(11.1-27.3)$ \\
FEV1 summer & $18.5(9.8-27.1)$ \\
$22-30 \mathrm{ppb}$ & $11.6(3.2-20.1)$ \\
$30<38 \mathrm{ppb}$ & $16.8(8.5-25.0)$ \\
$38-46 \mathrm{ppb}$ & $-16.4(-24.6--8.3)$ \\
FVC winter & $-15.0(-21.6--8.4)$ \\
$4<12 \mathrm{ppb}$ & $-11.8(-18.4-5.3)$ \\
$12-<20 \mathrm{ppb}$ & $-10.9(-19.7--2.1)$ \\
$20<28 \mathrm{ppb}$ & $-11.2(-18.5--3.9)$ \\
FEV1 winter & $-9.9(-17.4-2.4)$ \\
$4<12$ ppb & \\
$12-<20 \mathrm{ppb}$ & \\
$20<28$ ppb & \\
\hline &
\end{tabular}

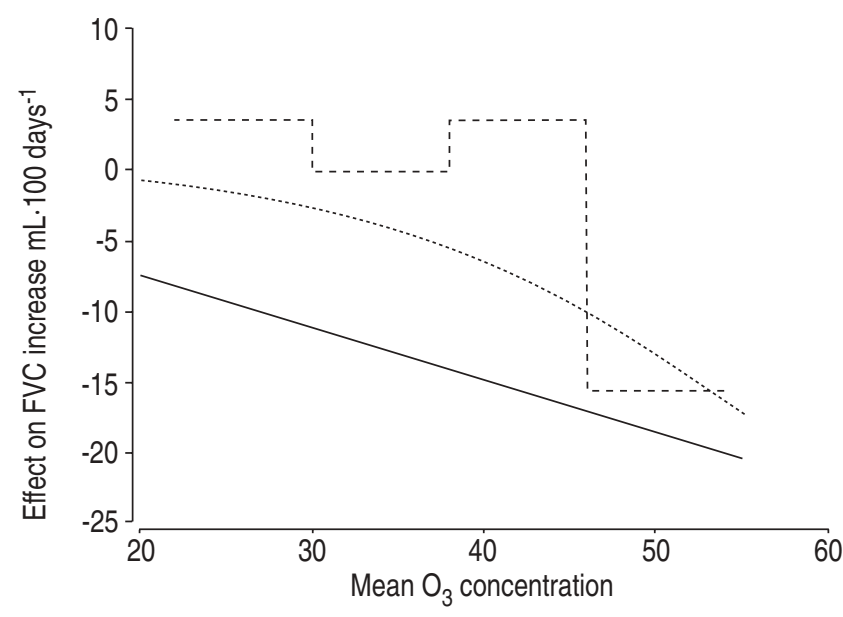

Fig. 4.-Estimated functional influence of mean ozone $\left(\mathrm{O}_{3}\right)$ exposure on forced vital capacity (FVC) increase in summer: - : linear; ----: classified; $\cdots \cdots \cdots \cdot$ : fractional polynomials.

of semi-annual mean $\mathrm{O}_{3}$ concentration. The estimated relationship between semi-annual mean $\mathrm{O}_{3}$ concentration and FVC increase in summer is shown in figure 4 together with an estimated linear relationship and a division of semi-annual mean $\mathrm{O}_{3}$ concentrations into four classes.

Based on these results, analysis was performed by dividing semi-annual mean $\mathrm{O}_{3}$ concentrations into four classes and revealed significantly higher increases in FVC and FEV1 during summer for all classes in comparison to the highest exposure (46-54 ppb) (table 3). For example, the semi-annual mean $\mathrm{O}_{3}$ exposure in summer of $22-30 \mathrm{ppb}$ (compared to 46-54 ppb) was associated with an estimated higher increase in FVC (FEV1) of 19.2 (18.5) $\mathrm{mL} \cdot 100$ days $^{-1}$ (table 3). An inverse effect occurred for the winter periods. For instance, the semi-annual mean $\mathrm{O}_{3}$ exposure in winter of 4-12 ppb (compared to 28-36 ppb) was associated with an estimated lower increase in FVC (FEV1) of $-16.4(-10.9) \mathrm{mL} \cdot 100$ days $^{-1}$ (table 3).

Interaction between a possible "country effect" and the possible $\mathrm{O}_{3}$ effect was tested and found not to be present. Introducing medium-term $\mathrm{NO}_{2}$, medium-term $\mathrm{SO}_{2}$, rhinitis when performing the test, or fieldworkers as a possibly influencing variable did not change the results concerning $\mathrm{O}_{3}$ effects and were therefore not considered in the final models.

To identify combined effects, stratified analyses of the final $\mathrm{O}_{3}$ exposure class model were conducted, stratifying the population with respect to sex, pollen sensitisation, asthma, and a diagnosis of hayfever. No significant interaction could be found (data not shown).

An age-stratified analysis was performed to investigate the possibility of a higher vulnerability in younger children, where groups of approximately equal size were formed, separated according to their age at the first investigation. No differences could be found for summer effects, but in the analysis of winter periods the effect was significantly less pronounced in younger children (data not shown).

For comparative reasons, the analysis was repeated using area-based categories, where a significantly higher increase during summer was found in the low but not in the medium $\mathrm{O}_{3}$ exposure category compared to the high exposure category for both FVC $\left(8.0 \mathrm{~mL} \cdot 100\right.$ days $\left.^{-1}\right)$ and FEV1 $\left(9.3 \mathrm{~mL} \cdot 100\right.$ days $^{-1}$; table 4). In contrast, increases in winter were significantly lower in the low exposure category compared to the high exposure category $\left(-9.7 \mathrm{~mL} \cdot 100\right.$ days $^{-1}$ for FVC and $-7.5 \mathrm{~mL} \cdot 100$ days $^{-1}$ for FEV1). 
To investigate the hypothesis that a positive $\mathrm{O}_{3}$ effect in winter can be viewed as a catch-up effect of a preceding negative $\mathrm{O}_{3}$ effect in summer, regression coefficients were calculated where summer FVC/FEV1 increases are used to predict increases in the succesive winter. The regression coefficients were estimated separately for $\mathrm{O}_{3}$ exposure areas $(\mathrm{L} / \mathrm{M} / \mathrm{H})$, and the parameter estimates $(\mathrm{PE})$ and their standard errors (SE) are for FVC increase: $\mathrm{PE}=-0.165, \mathrm{SE}=0.022(\mathrm{~L})$; $\mathrm{PE}=-0.154, \mathrm{SE}=0.025 \quad(\mathrm{M}) ; \mathrm{PE}=-0.319, \mathrm{SE}=0.031 \quad(\mathrm{H})$ for summer 1, winter 1; $\mathrm{PE}=-0.240, \mathrm{SE}=0.026$ (L); $\mathrm{PE}=-0.283$, $\mathrm{SE}=0.026(\mathrm{M}) ; \mathrm{PE}=-0.344, \mathrm{SE}=0.025(\mathrm{H})$ for summer 2 , winter 2; $\mathrm{PE}=-0.351, \quad \mathrm{SE}=0.046 \quad(\mathrm{~L}) ; \mathrm{PE}=-0.319, \mathrm{SE}=0.029 \quad(\mathrm{M})$; $\mathrm{PE}=-0.344, \mathrm{SE}=0.030(\mathrm{H})$ for summer 3 , winter 3 . The $\mathrm{PE}$ for the summer $1 /$ winter 1 model is markedly higher in the high exposure area, whereas PEs are of similar size for the following seasons. This effect is even more prominent when analysing FEV1 increases (data not shown).

For 1,869 children with at least six lung function tests, individual regression coefficients for $\log (\mathrm{FVC})$ and $\log (\mathrm{FEV} 1)$ regressed on $\log \left(\right.$ height) and short-term $\mathrm{O}_{3}$ exposure were obtained. The individual regression slopes were then related to mean summer $\mathrm{O}_{3}$ exposure over four periods, sex, passive smoke exposure, and age at first lung function test as independent variables in a second regression model. No association between growth rates and mean summer $\mathrm{O}_{3}$ could be shown for FVC and FEV1 over a 3.5 yearly period.

\section{Discussion}

Based on 12,919 observations of schoolchildren's lung growth, higher increases in FVC and FEV1 were observed in the case of low ambient $\mathrm{O}_{3}$ exposure during summer when high exposure served as a reference. In turn, during winter, exposure to lower ambient $\mathrm{O}_{3}$ concentrations was associated with a lower increase in FVC and FEV1 in comparison to exposure to high concentrations. However, low exposure during summer represents low exposure also during winter. Thus the current authors postulate that the winter results are merely a reversibility pattern regarding $\mathrm{O}_{3}$ effects during summer. This is especially the case for the area-based analysis (table 4), where almost the same individuals were in the same exposure category for both summer and winter. That would mean that only the category with high exposure during summer $(\mathrm{H}$; 3.5-yr average $32.0-40.6 \mathrm{ppb})$ differs from the other groups, and during winter decreasing exposure reveals opposite differences in the changes of FVC and FEV1. Results from separate seasonal analyses show however no consistent effects: there was a clear effect observed in the first

Table 4.-Parameter estimates from generalised estimation equation models" for ozone $\left(\mathrm{O}_{3}\right)$ exposure categories (pooled analysis for seasons) with "high exposure" as reference

\begin{tabular}{|c|c|c|}
\hline \multirow[t]{2}{*}{ Increase in: } & \multicolumn{2}{|c|}{$\begin{array}{c}\text { Parameter estimates for increase } \\
\left(\mathrm{mL} \cdot 100 \text { days }^{-1}\right) \text { for } \mathrm{O}_{3} \text { exposure categories } \\
\text { compared to "high" }^{\text {compored }}\end{array}$} \\
\hline & Medium & Low \\
\hline FVC summer & $-0.03(-5.0-4.9)$ & $8.0(1.8-14.3)$ \\
\hline FVC winter & $-5.8(-10.3-1.3)$ & $-9.7(-14.5-4.9)$ \\
\hline FEV1 summer & $-0.1(-5.3-5.1)$ & $9.3(3.0-15.6)$ \\
\hline FEV1 winter & $-3.1(-8.2-2.0)$ & $-7.5(-12.7-2.4)$ \\
\hline
\end{tabular}

Data are presented as parameter estimate ( $95 \%$ confidence intervals). FVC: forced vital capacity; FEV1: forced expiratory volume in one second. \#: Adjusted for sex, age and height at start of the time period, passive smoke exposure, time period, short-term $\mathrm{O}_{3}$ exposure at start and end of time period. two study years and a much broader variability of effects in the later part of the study period. These findings point to a possible medium-term effect (in summer seasons) of high ambient $\mathrm{O}_{3}$ concentrations on schoolchildren's lung growth, which seems to be transitoric.

The current authors have presented a pooled analysis of two data sets collected in Austria (1994-1996) and Germany (1996-1999). FVC \% pred was found to be higher in German regions but no clear differences for FEV1\% pred could be observed. The pooling of different data sets might thus give rise to study effects in the analysis. However, all technical details (spirometry protocol, hardware, software, calibration of the spirometer) were standardised before the beginning of the study, and all staff were trained centrally. The fact that differences in lung function measurements could only be observed for $\mathrm{FVC} \%$ pred but not for FEV1 \% pred further hints at the absence of systematic differences. Interaction terms of the factors "study" and "O ${ }_{3}$ exposure" were considered in the statistical analysis and were found to be insignificant for the main results (data not shown). The pooled analysis of two large data sets thus has the advantage of greatly increasing the power of the analysis. Furthermore, it was possible to include a broader range of ambient $\mathrm{O}_{3}$ exposure in the analysis, leading to more stability in the statistical parameter estimates.

In earlier studies assessment of medium-term (referring to months) or long-term effects (referring to years) of air pollution was often done by conducting a cross-sectional study where people from differently exposed areas were compared [28, 29]. The longitudinal design of this study offers the opportunity of comparing lung growth measurements of the same child to each other, which reduces in particular the possibility of a migration bias (people who become ill will tend to migrate to healthier areas [30]).

One major problem in the assessment of adverse health effects of air pollutants is the choice of an adequate exposure variable. In order to address this problem, two approaches were chosen, one consisting of dividing the study regions into three exposure categories low/medium/high, and one where semi-annual mean $\mathrm{O}_{3}$ concentrations were used. Defining high or low exposed geographical areas as a surrogate variable for air pollution exposure is a robust but rough means: it might be the source of potential bias caused by the confounding of other air pollutants. In order to obtain an exposure variable that is more specific, mean semi-annual $\mathrm{O}_{3}$ concentrations were calculated. Especially in the context of a longitudinal study this approach allows exposure which varies from season to season to be taken into consideration.

Stationary monitors were used to assess air pollution exposure. Some authors have described dependencies between air pollution effects and time spent outdoors [15, 16]. More accurate measurements could possibly have been obtained by the use of personal samplers which seems however hardly feasible for a large study population over such a long study period. The present authors have investigated the association between stationary monitor measurements, personal sampling, and short-term effects of these measurements on lung function in a subgroup of the study population [31] and hence consider that stationary monitors provide valid measurements.

The shape of the function chosen to describe the $\mathrm{O}_{3}$ exposure effect was considered carefully. Transformations of the independent exposure variable in the linear regression model were investigated systematically and revealed a nonlinear relationship between $\mathrm{O}_{3}$ exposure and lung growth. In general, the most robust method is the classification of semi-annual mean $\mathrm{O}_{3}$ concentrations into several classes and was applied to the current study's data. The comparison of the two $\mathrm{O}_{3}$ exposure assessments (considering area-based categories versus semi-annual $\mathrm{O}_{3}$ concentrations) shows that 
the same conclusion is reached, namely transitoric effects of $\mathrm{O}_{3}$ exposure on lung function, but the details of the evaluation appear different: table 3 shows that in the first model $\left(\mathrm{O}_{3}\right.$ concentrations) effects are outstanding for all "lower" classes (22-46 ppb) in comparison to the highest class (46-54 ppb; table 3); table 4 shows that for the second model (area-based) effects are outstanding for the low exposure category in comparison to the reference with high exposure. Thus in general there is no contradiction. The approach using $\mathrm{O}_{3}$ concentrations underlines a limit value of approximately $46 \mathrm{ppb}$.

The effect of other air pollutants such as $\mathrm{NO}_{2}, \mathrm{SO}_{2}$, particulate matter (PM10) or TSP on children's lung growth should also be investigated as it is a possible source of biased estimation. Therefore the final analysis was repeated (table 3 ) by introducing mean $\mathrm{SO}_{2}$ and mean $\mathrm{NO}_{2}$ values as confounding factors. The parameter estimates for $\mathrm{O}_{3}$ were very similar to the results presented in table 3 . It was concluded that the effect of other air pollutants on children's lung growth may be present but does not interfere with the effects describing at present. Concerning PM10/TSP, no measurements were taken in three of the study sites. The present authors therefore refer to earlier work [18, 21, 32] where effects of PM10 exposure did not alter the findings with respect to $\mathrm{O}_{3}$.

Short-term effects of exposure to $\mathrm{O}_{3}$ have been extensively studied [1-13], whereas only few investigations dealing with medium-term or long-term effects have been published [14-18, 21].

Long-term effects of $\mathrm{O}_{3}$ on lung growth have been assessed in animal studies, where subchronic effects of $\mathrm{O}_{3}$ were observed in rats using markers of cell injury [33-36]. TYLER et al. [33] concluded that $\mathrm{O}_{3}$ inhalation by young rats altered lung growth and development in ways likely to be detrimental, and that those changes persisted after $\mathrm{O}_{3}$ exposure had been terminated [34]. VAN BREE et al. [36] found that some of the markers (protein and albumin content, neutrophil influx in bronchoalveolar fluid) returned to control levels within a few days after termination of exposure, whereas other markers (alveolar macrophage response, presence of terminal bronchioles, thickening of ductular septa by enhanced cellularity, collagen formation) were persistently elevated even after exposure. Thus, inflammatory processes could result also in long-term effects on lung growth even under changing exposure. Assuming a cumulative effect of natural exposure, ACKERMANN-LIEBRICH et al. [28] found no signs of $\mathrm{O}_{3}$ influences on FVC and FEV1 in adulthood. In contrast, the cross-sectional analysis of a study in South California showed a statistically significant association between $\mathrm{O}_{3}$ exposure and lower FVC and FEV1 for male children spending much time outdoors and for female children with asthma [14]. Based on a longitudinal design KINNEY et al. [17] observed a larger decline in FEV1 (44 mL) in the area with highest $\mathrm{O}_{3}$ exposure over one summer period in healthy young adults working outdoors. The estimated average $\mathrm{O}_{3}$ effects of the Austrian study by FRISCHER et al. [18], which constitutes a part of the current authors' data, were $-1.8(-2.9) \mathrm{mL} \cdot 100$ days $^{-1} \cdot \mathrm{ppb}^{-1}$ increase in FVC (FEV1) in three summer periods. The average summer $\mathrm{O}_{3}$ effect observed by the current authors corresponds to an effect of about $-0.80(-0.78) \mathrm{mL} \cdot 100 \mathrm{days}^{-1} \cdot \mathrm{ppb}^{-1}$ increase in FVC (FEV1) if it were considered to be linear, or -19.2 (-18.5) $\mathrm{mL} \cdot 100$ days $^{-1}$ for high exposure (46-54 ppb) compared to low exposure (22-30 ppb). They are thus slightly weaker than the effects described by FRISCHER et al. [18]. In an earlier article the current authors' group reported summer $\mathrm{O}_{3}$ effects on the difference in FVC (FEV1) increase of -27.8 and -26.6 $(-30.3$ and -32.2$) \mathrm{mL} \cdot 100$ days $^{-1}$, when comparing high exposure areas to low exposure areas over two summers
[21]. Thus the current results of negative effects of $\mathrm{O}_{3}$ averaged over four summer seasons are in accordance with earlier results and speak in favour of a medium-term effect on schoolchildren's lung growth.

However, the $\mathrm{O}_{3}$ effects observed during winter periods are of roughly the same size and show reversed signs: a lower increase in FVC (FEV1) of -16.4 (-10.9) $\mathrm{mL} \cdot 100$ days $^{-1}$ for low exposure (4-12 ppb) compared to high exposure (28-36 ppb). Regression coefficients where summer FVC/FEV1 increases are used to predict increases in the successive winter were calculated to support the current authors' view that the winter $\mathrm{O}_{3}$ effect can be interpreted as a catch-up effect. The estimated regression slope was found to be markedly higher in the high exposure area than in the other areas for the first season (summer 1, winter 1), but not for the following seasons. These regression models were used to relate summer and winter FVC (FEV1) increases of the children directly and indicate that winter $\mathrm{O}_{3}$ effects can be viewed as a reversibility effect.

In addition these results are in accordance with those of FRISCHER et al. [18] and KoPP et al. [21]. Longer-lasting effects of $\mathrm{O}_{3}$ on children's lung growth thus seem to be at least questionable. The longitudinal analysis of a South Californian cohort [15] points in the same direction, showing no signs of an $\mathrm{O}_{3}$ effect over a time period of 4 yrs, and although the results of the second cohort [16] showed effects of $\mathrm{O}_{3}$ on changes in PEFR (difference in annual per cent growth rates from the least to the most polluted community is $-1.21 \%$ ) it found none on changes in FVC and FEV1.

There were varying results from the seasonal analyses. A clear effect of $\mathrm{O}_{3}$ on children's lung growth in the first 2 yrs of the study was not repeated in the later part of the study. Two possible explanations can be taken into consideration. One reason might be that younger children are possibly more vulnerable than older children, an assumption which can also be supported by the findings of the current authors' earlier studies [18, 21], where consistent effects were found for the first 2-yr study period but not in the analysis of the third study year of the Austrian data. The age-stratified analysis revealed a significantly less pronounciated effect in winter for younger children. Since "winter ozone effects" are interpreted as a catch-up of harmful summer effects, this result can be viewed in support of the hypothesis that younger children are more vulnerable.

Another reason might be the variation of $\mathrm{O}_{3}$ exposure during different study summer periods, where especially in the Austrian high $\mathrm{O}_{3}$ exposure regions the highest mean $\mathrm{O}_{3}$ concentrations were observed during the first part of the study. This aspect again emphasises the importance of accurate exposure measurement. The common analysis of the whole study period in this case presents an estimated averaged $\mathrm{O}_{3}$ effect over summer periods with different exposure levels.

\section{Conclusion}

An effect of summer ozone exposure on the growth-related increase in forced vital capacity and forced expiratory volume in one second in schoolchildren was observed only for the highest ozone concentrations during the first 2 yrs of the study. In the following winter seasons the pattern was reversed. It is thus concluded that medium-term effects on schoolchildren's lung growth are possibly present. However, in the long-term no association between growth rates and mean summer $\mathrm{O}_{3}$ could be shown for forced vital capacity and forced expiratory volume in one second. Medium term effects thus might be at least partially reversible. 


\begin{abstract}
Acknowledgements. The authors would like to thank G. Bär, H. Schulz, C. Schneider, E. Strauch, J. Laule, C. Prazak, F. Riedinger, S. Glaser, B. Holler, G. Holderried, K. Nemat, A. Wolf, B. Rudolphi, B. Werner, A. Stelzer, N. Schoofs for their outstanding collaboration during the field study. Data on air pollution exposure was kindly provided by the Regional Protection Agency (LFU, Baden-Württemberg; NUMBIS, Nieder-Österreich; LUIS, Steiermark).
\end{abstract}

\section{References}

1. Braun-Fahrländer C, Künzli N, Domenighetti G, Carell CF, Ackermann-Liebrich U. Acute effects of ambient ozone on respiratory function of Swiss schoolchildren after a 10minute heavy exercise. Pediatr Pulmonol 1994; 17: 169-177.

2. Hoek G, Brunekreef B, Kosterink P, Van den Berg R, Hofschreuder P. Effect of ambient ozone on peak expiratory flow of exercising children in the Netherlands. Arch Environ Health 1993; 48: 27-32.

3. Castillejos M, Gold DR, Damokosh AI, et al. Acute effects of ozone on the pulmonary function of exercising schoolchildren from Mexico City. Am J Respir Crit Care Med 1995; 152: 1501-1507.

4. Kinney PL, Thurston GD, Raizenne M. The effects of ambient ozone on lung function in children: a reanalysis of six summer camp studies. Environ Health Perspect 1996; 104: 170-174.

5. Hoek G, Fischer P, Brunekreef B, Lebret E, Hofschreuder P, Mennen MG. Acute effects of ambient ozone on pulmonary function of children in the Netherlands. Am Rev Respir Dis 1993; 147: 111-117.

6. Neas LM, Dockery DW, Koutrakis P, Tollerud DJ, Speizer FE. The association of ambient air pollution with twice daily peak expiratory flow rate measurements in children. $\mathrm{Am}$ J Epidemiol 1995; 141: 111-122.

7. Castillejos M, Gold DR, Dockery D, Tosteson T, Baum T, Speizer FE. Effects of ambient ozone on respiratory function and symptoms in Mexico City schoolchildren. Am Rev Respir Dis 1992; 145: 276-282.

8. Gold DR, Damokosh AI, Pope CA, et al. Particulate and ozone pollutant effects on the respiratory function of children in Southwest Mexico City. Epidemiol 1999; 10: 816. (published erratum appears in Epidemiol 1999; 10: 470).

9. Jalaludin BB, Chey T, O'Toole BI, Smith WT, Capon AG, Leeder SR. Acute effects of low levels of ambient ozone on peak expiratory flow rate in a cohort of Australian children. Int J Epidemiol 2000; 29: 549-557.

10. Chen PC, Lai YM, Chan CC, Hwang JS, Yang CY, Wang JD. Short-term effects of ozone on the pulmonary function of children in primary school. Environ Health Perspect 1999; 107: 921-925.

11. Linn WS, Shamoo DA, Anderson KR, et al. Short-term air pollution exposures and responses in Los Angeles area schoolchildren. J Expo Anal Environ Epidemiol 1996; 6: 449-472.

12. Ulmer C, Kopp M, Ihorst G, Frischer T, Forster J, Kuehr J. Effects of ambient ozone exposures during the spring and summer of 1994 on pulmonary function of schoolchildren. Pediatr Pulmonol 1997; 23: 344-353.

13. Bohnet W, Kuehr J, Kopp M, Ulmer C, Ihorst G, Forster J. Effekt der natürlichen Ozonexposition auf lungenmechanische Messgrößen bei Grundschülern. Monatsschr Kinderheilkd 1998; 146: 617-621.

14. Peters JM, Avol E, Gauderman WJ, et al. A study of twelve Southern Californian communities with differing levels and types of air pollution. II: Effects on pulmonary function. $\mathrm{Am}$ J Respir Crit Care Med 1999; 159: 768-775.

15. Gauderman WJ, McConnell R, Gilliland F, et al. Association between air pollution and lung function growth in Southern California children. Am J Respir Crit Care Med 2000; 162: 1383-1390.
16. Gauderman JW, Gilliland GF, Vora H, et al. Association between air pollution and lung function growth in Southern Californian children. Results from a second cohort. $\mathrm{Am}$ $J$ Crit Care Med 2002; 166: 76-84.

17. Kinney PL, Lippmann M. Respiratory effects of seasonal exposures to ozone and particles. Arch Environ Health 2000; 55: 210-216.

18. Frischer T, Studnicka M, Gartner C, et al. Lung function growth and ambient ozone. A three-year population study in school children. Am J Respir Crit Care Med 1999; 160: 390396.

19. Tager I. Air pollution and lung function growth. Is it ozone? Am J Respir Crit Care Med 1999; 160: 387-389.

20. Weiss ST, Ware JH. Overview of issues in the longitudinal analysis of respiratory data. Am J Crit Care Med 1996; 154: S208-S211.

21. Kopp M, Bohnet W, Frischer T, et al. Effects of ambient ozone on lung function in children over a two-summer period. Eur Respir J 2000; 16: 893-900.

22. Dockery DW, Berkey CS, Ware JH, Speizer FE, Ferris BG jr. Distribution of forced vital capacity and forced expiratory volume in one second in children 6 to 11 years of age. $\mathrm{Am}$ Rev Respir Dis 1983; 128: 405-412.

23. Asher MI, Keil U, Anderson HR, et al. International Study of Asthma and Allergies in Childhood (ISAAC): rationale and methods. Eur Respir J 1995; 8: 483-491.

24. Meinert R, Frischer T, Karmaus W, Kuehr J. Influence of skin prick test criteria on estimation of prevalence and incidence of allergic sensitization in children. Allergy 1994; 49: $526-532$

25. Sauerbrei W, Royston P, Bojar H, Schmoor C, Schumacher $\mathrm{M}$ and the German Breast Cancer Study Group. Modelling the effects of standard prognostic factors in node-positive breast cancer. Br J Cancer 1999; 79: 1752-1760.

26. Liang KY, Zeger SL. Longitudinal data analysis using generalized linear models. Biometrika 1986; 73: 13-22.

27. Ware $\mathbf{J H}$, Weiss S. Statistical issues in longitudinal research on respiratory health. Am J Respir Crit Care Med 1996; 154: S212-S216.

28. Ackermann-Liebrich U, Leuenberger P, Schwartz J, et al. Lung function and long term exposure to air pollutants in Switzerland. Study on air pollution and lung diseases in adults (SAPALDIA) team. Am J Respir Crit Care Med 1997; 155: 122-129.

29. Jedrychowski W, Flak E, Mroz E. The adverse effects of low levels of ambient air pollutants on lung function growth in preadolescent children. Environ Health Perspect 1999; 107: 669-674.

30. Sunyer J. Urban air pollution and chronic obstructive pulmonary disease: a review. Eur Respir J 2001; 17: 10241033.

31. Strauch E, Baer G, Bohnet W, et al. Short-term effect of ozone on pulmonary function under consideration of measurements with personal samplers and fixed site monitors in schoolchildren. Eur Respir $J$ 2000: 344s.

32. Horak F, Studnicka M, Gartner C, et al. Particulate matter and lung function growth in children: a 3-yr follow-up study in Austrian schoolchildren. Eur Respir J 2002; 19: 838-845.

33. Tyler WS, Tyler NK, Last JA, Bartsow TJ, Magliano DJ, Hinds DM. Effects of ozone on lung and somatic growth. Pair fed rats after ozone exposure and recovery periods. Toxicology 1987; 46: 1-20.

34. Tyler WS, Tyler NK, Last JA, Gillespie MJ, Barstow TJ. Comparison of daily and seasonal exposures of young monkeys to ozone. Toxicology 1988; 50: 131-144.

35. Chang L, Miller FJ, Ultman J, et al. Alveolar epithelial cell injuries by subchronic exposure to low concentrations of ozone correlate with cumulative exposure. Toxicol Appl Pharmacol 1991; 109: 219-234.

36. Van Bree L, Dormans JA, Boere AJ, Rombout PJ. Time study on development and repair of lung injury following ozone exposure in rats. Inhal Toxicol 2001; 13: 703-718. 